Hispania Sacra, LXI

124, julio-diciembre 2009, 621-647, ISSN: 0018-215-X

\title{
SOBRE LOS MARGINALIA EN LA CARTA APOLOGÉTICA (1735) DE MANUEL FERNÁNDEZ SIDRÓN: LECTURAS EN LATÍN Y VERNÁCULO DE UN FRANCISCANO CANARIO
}

POR

\author{
Francisco SALAS SALGAdo \\ Universidad de La Laguna
}

\begin{abstract}
RESUMEN
A los registros de diverso tipo que existen sobre los libros que conformaron muchas bibliotecas en Canarias, se añade la referencia precisa que en determinadas obras se puede encontrar. Es el caso de la Carta apologética (1735), obra debida al franciscano Manuel Fernández Sidrón, en cuyos márgenes existe todo un cúmulo de citas de autores y obras, del cual va a tratar el siguiente trabajo. Aunque es lógico considerar que esta obra tiene unos fines concretos, estas citas marginales descubren un universo de libros que no sólo tienen que ver con unos gustos de lecturas particulares, sino también generales.
\end{abstract}

PALABRAS ClAVE: Biblioteca. Latín. Vernáculo. Franciscanos. Siglo XVIII. Canarias.

\section{ON MARGINALIA IN MANUEL FERNÁNDEZ SIDRÓN'S CARTA APOLOGÉTICA (1735): LATIN AND VERNACULAR READINGS OF A CANARIAN FRANCISCAN}

\begin{abstract}
The quality of records of all sorts regarding the type of books found in the libraries of the Canary Islands is enriched on some occasions by the inclusion of precise references to specific works. Such is the case of the Apologetic Letter (1735), by the Franciscan Manuel Fernández Sidrón. The aim of this work is to analyze the margins of this letter, where a considerable amount of quotations and references to authors and works can be appreciated. Althought the acceptance of
\end{abstract}


a particular aim for these references is taken for granted, the marginal quotations disclose a whole world of books revealing not only the personal readings and tastes of the author, but also more general interests.

KEY WORDS: Library. Latin. Vernacular. Franciscans. 18th Century. Canary Islands.

Recibido/Received 03-10-2008

Aceptado/Accepted 11-12-2008

\section{INTRODUCCIÓN}

El Fondo Antiguo de la Biblioteca de la Universidad de La Laguna conserva un manuscrito que, en su f. $1^{\mathrm{r}}$., lleva por título Carta Apologética en que se defienden las cartas de el Gran Padre San Francisco de Paula, las profecías de San Malaquías, arzobispo, y los oráculos de las Sibylas, contra la opinión de el M. R. P. Fr. Benito Gerónimo Feijoo, Maestro General Abad y Monge Benedictino $^{1}$. Hace tiempo fue descrito por A. Millares Carlo en su Ensayo de una biobibliografía y, posteriormente, junto a M. Hernández González, en su imprescindible Biobibliografía de escritores canarios ${ }^{2}$. Fechado en el año 1735, se debe su realización al franciscano canario Manuel Fernández Sidrón.

El autógrafo, seguramente no definitivo, tiene la particularidad de llevar en los márgenes una gran cantidad de referencias, particularmente de obras y autores varios, escritas mayormente en latín, sobre las cuales va a girar este. Considero que la atención a estos marginalia se revela importante, en tanto que es una forma inmediata de conocer unos textos, más o menos cercanos, que con toda seguridad conoció aquel franciscano y utilizó en el ranscurso de redacción de Carta apologética. En definitiva, pretendo acercarme, a través de estas referencias y dentro de la lógica parcialidad -hecho que ha de ser tenido muy en cuenta- a la posible (si no real) cultura libresca de un autor canario, a un universo de libros (impuesto o no), muchos de uso común en la Orden a la que pertenecía, cuya validez pudiera trascender la propia época y los propios límites geográficos 3 .

\footnotetext{
${ }^{1}$ Aclaro, desde ahora, que en el presente trabajo se respeta la ortografía del texto de la Carta apologética, y sólo se actualiza la puntuación y acentuación.

2 A. Millares Carlo, Ensayo de una bio-bibliografía de escritores naturales de las Islas Canarias (Siglos XVI, XVII y XVIII), Madrid, 1932, pp. 210-212; y A. Millares CARLO-M. HernándeZ SuÁREZ, Biobibliografía de escritores canarios (Siglos XVI, XVII y XVIII), con la colaboración de A. Vizcaya Carpenter y A. Millares Sall, t. III, Las Palmas de Gran Canaria, 1979, pp. 105-106. CFr. recientemente, P. Fernández Palomeque-Ma . L. Morales Ayala, Catálogo de manuscritos de la Biblioteca Universitaria de La Laguna, La Laguna, 2002, p. 27.

${ }^{3}$ Sobre esta línea de investigación vengo trabajando hace unos años, siempre desde el terreno de la Filología Clásica. Cfr. de este modo, F. SALAS SALGADO, «Las notas de la censura latina del francisca-
}

Hispania Sacra, LXI

124, julio-diciembre 2009, 621-647, ISSN: 0018-215-X 
Si nos atenemos a lo realizado, a este respecto, sobre la Orden en las Islas (esta tarea en general se reconoce ingente ${ }^{4}$ ) sólo contamos con dos inventarios realizados en el siglo XIX ${ }^{5}$, publicados por fray Diego de Inchaurbe, frente a varios trabajos realizados sobre las bibliotecas de los franciscanos españoles de la Península ${ }^{6}$. Sobre todo, las noticias que se ofrecen en territorio insular afectan a la consolidación y expansión de la Orden.

Pero antes de pasar a desglosar e identificar estas anotaciones, vienen bien unos datos que, dentro de las lógicas limitaciones, hagan a conocer a nuestro autor y ofrezcan algunas características de esta obra, sobre todo para que sitúen al posible lector en el contexto cultural e histórico que dio lugar a su composición.

no Andrés de Abreu», Cartas diferentes. Revista Canaria de Patrimonio Documental, 1 (2005), 119156; e ID., «Las anotaciones marginales en Convalecencia del alma de Pedro Álvarez de Lugo y Usodemar: una aproximación a la cultura literaria del Barroco en Canarias», en J. Ma ${ }^{a}$. MAESTRE MAESTREJ. Pascual Barea-L. Charlo Brea (eds.), Humanismo y pervivencia del Mundo Clásico. Homenaje al Profesor Antonio Prieto (en prensa). Otros trabajos sobre M. Fernández Sidrón desde la perspectiva filológica, especialmente clásica, son: J. A. GonZÁLEZ MARRERO, «La Carta Apologética de M. Fernández Sidrón de 1735: una versión castellana del texto de J. Colgan De egressione familie Sancti Brendani», Revista de Filología de la Universidad de La Laguna, 15 (1997), 71-85; F. SAlAs SALGado, «Poemas latinos en la Carta apologética de Manuel Fernández Sidrón», Revista de Filología de la Universidad de La Laguna, 25 (2006), 549-558; e ID., «La Carta apologética (1735) de Manuel Fernández Sidrón y la cultura latina de su tiempo», Fortunatae, 18 (2007), 183-199.

${ }^{4}$ De este modo se refiere FrAY JosÉ GARCía SANTOS, «Tres nombres para la historiografía franciscana en Canarias», Homenaje a Antonio de Bethencourt Massieu, Ediciones del Cabildo de Gran Canaria, Las Palmas de Gran Canaria, 1995, p. 651: «La historia de la Orden Franciscana en Canarias está todavía sin escribir. Conocemos algunos aspectos de los grandes misioneros del siglo XV ... pero ignoramos capítulos tan señeros, como su papel evangelizador, sobre todo en las múltiples ermitas y capellanías diseminadas por los campos; los diversos estadios seguidos en la preparación intelectual de sus frailes, iniciados en la Universidad de Ossuna o en el Colegio franciscano de San Buenaventura de Sevilla, que brillaba con luz propia en el cielo de los estudios eclesiásticos; la aportación a la cultura popular por medio de sus cátedras de Gramática, obligatorias en todos los conventos, donde impartían gratuitamente la enseñanza primaria ...».

${ }^{5}$ Fr. Diego De InChaURBe, «Inventario del Convento Franciscano de San Lorenzo de La Orotava (Tenerife)», Archivo Ibero-Americano, 30 (1948), 253-272; e ID., «Inventario de la Biblioteca del suprimido convento de San Pedro de Alcántara de la villa de Santa Cruz de Tenerife», Archivo Ibero-Americano, 35 (1949), 384-402.

${ }^{6}$ Como ejemplo, y sin ánimo de exhaustividad, del interés por la cultura libresca de los franciscanos en tierras peninsulares, véase S. ZUSKA POLASEK, «Catálogo de incunables de la biblioteca de los franciscanos de Valencia», Archivo Ibero-Americano, 160 (1980), 291-314; J. A. DE Freitas CARvalHO, «Libros e lecturas de espiritualidade franciscanos na segunda metade do seculo XV em Portugal e Espanha», Carthaginensia: Revista de estudios e investigación, 11 (1991), 127-228; M. DE CASTRO, «La biblioteca de los Franciscanos de Val de Dios, de Santiago (1222-1230)», Iacobus: revista de estudios jacobeos y medievales, 9-10 (2000), 29-44; O. REY CASTELAO, «Las bibliotecas de los frailes terceros franciscanos de Galicia: un toque de innovación», en M. Romaní-A. Novoa (coords), Homenaje a José García Oro, 2002, pp. 251-266. Cfr. también en esta misma revista, R. M. Pérez García, «La biblioteca del convento de San Antonio de Padua de Lora del Río: libros de autor franciscano (1646)», Hispania Sacra, 116 (2005), 745-794. 


\section{MANUEl FernÁNDEZ SidRÓN: UNA EXIGUA BIOGRAFÍA}

Las noticias del devenir vital que se conocen de este autor son escasas, amén de imprecisas. Así, al referirse al lugar y fecha de su nacimiento, algunos investigadores los sitúan en la villa de La Orotava, Tenerife, posiblemente en 1669, apuntando que su muerte debió acaecer por los años 1747 ó 17487.

Otros pocos datos más se obtienen de las referencias que aparecen en las obras conocidas de este franciscano. Así un escrito suyo anterior ${ }^{8}$ (sólo conozco de esta obra la descripción que hacen A. Millares Carlo y M. Hernández Suárez), Contextos y discursos sobre la gran Profecía, que cerca de la religión de los Crucíferos, la última que se ha de fundar en la Iglesia, hizo S. Francisco de Paula, ynclyto Patriarca de la Sagrada religión de los PP.s Mínimos..., refiere, en la portada, que en 1716, fecha inicial de la redacción de esta obra, era lector de Prima de Sagrada Teología en el Convento de San Miguel de las Victorias en la ciudad de La Laguna ${ }^{9}$. A renglón seguido, se dice que fue corregido por Fernández Sidrón en el año de 1728, momento en que era lector jubilado y examinador sinodal del obispado. El proceso de redacción no debió acabar aquí, ya que al fin del texto, en el folio $212 \mathrm{v}$., aparece: «Fenecido hoy día 30 de enero de el año de 1747 y de mi edad 78 cumplidos». Si consideramos esta fecha, debía tener en el momento de realización de la Carta apologética 66 años.

También en esta obra se ofrece algún pequeño pormenor de su vida, pues en la portada se indican algunos cargos que ocupaba entonces, cuando era el «lector jubilado más antiguo del número de la Santa Provincia de San Diego de Canarias, examinador sinodal de su obispado y regente de los Estudios del Real Convento de la Inmaculada Concepción de Canarias de Nuestra Señora de la Ciudad de La Palma».

Por lo dicho anteriormente, se constata que la vida de nuestro autor transcurrió entre las islas de Tenerife y La Palma, siendo importante este último lugar, en cuanto aquí se escribió la Carta apologética.

7 E. Benito Ruano, «La polémica antifeijoniana en Canarias (un contradictor isleño del P. Feijoo)», II Coloquio de Historia Canario-Americana (1977), t. II, Las Palmas de Gran Canaria, 1979, 306. Remito, para no sobrecargar en exceso el presente artículo, a este trabajo donde se comentan las diversas partes de que consta la Carta apologética.

${ }^{8}$ Cfr. A. Millares Carlo-M. Hernández SuÁrez, Biobibliografía..., pp. 103-104.

${ }_{9}$ El convento de San Miguel de las Victorias fue fundado antes que el de la Concepción de La Palma. Sobre aquél decía J. de Viera y Clavijo (Noticias de la Historia General de las Islas Canarias, introducción y notas de A. Cioranescu, t. II, Santa Cruz de Tenerife, 1982, p. 722): «El convento es grande, con dos claustros y comunidad de cuarenta frailes, estudios de filosofía y teología, diversas dotaciones y memorias, impuestas por las principales casas de aquel país». Otras noticias en D. DE INCHAURBE y AldAPE, Compilación de artículos referentes a las Órdenes Franciscanas en Canarias, Las Palmas de Gran Canaria, 1983.

Hispania Sacra, LXI

124, julio-diciembre 2009, 621-647, ISSN: 0018-215-X 
De los conventos que frecuentó existen asimismo noticias. Así el convento de la Laguna fue el tercero que fundaron los franciscanos, con ayuda del adelantado Alonso Fernández de Lugo, con el título de San Miguel de las Victorias. Ayudaron a la fundación del mismo algunos habitantes principales de esta reciente ciudad. Entre los que pertenecieron a su comunidad «ha habido muchos de esclarecidas prendas, y en sus gran escuelas grandes maestros en la filosofía sutil y teología escolástica» ${ }^{10}$. Por su parte, el convento de la Concepción de La Palma fue el cuarto que tuvo la provincia de San Diego de Canarias. Como señala el historiador canario José de Viera y Clavijo, «el convento es grande, con dos claustros y comunidad de cuarenta a cincuenta frailes, estudios de filosofía y teología» 11 .

Por lo demás, amén de estos datos, poco más cabe añadir de este fraile ${ }^{12}$ del que Viera y Clavijo decía que era «hombre de ingenio y de talentos, pero enteramente aplicados al estudio de interpretar vaticinios y profecías. El abad Joaquín, San Malaquías, Bandarra, Nostradamo y otros visionario de este gusto fueron sus delicias» ${ }^{13}$.

\section{LOS ORÍGENES DE LA CARTA APOLOGÉTICA}

Si se atiende a lo que se refiere en los «Preludios» de la Carta apologética, parece que nuestro franciscano tuvo conocimiento en una estancia, en el año 1731, en la isla de Tenerife de algunos escritos del padre benedictino fray Jerónimo Feijoo que contradecían una obra suya anterior (es lógico que se piense en Contextos y discursos).

10 Ibidem, p. 718.

11 Ibidem, p. 722.

12 Debo a la amabilidad de Fray José García Santos la noticia de que quizás se trate este fraile de fray Manuel Rodríguez del Cabo Sidrón, quien fuera lector de Artes y discreto en el convento de San Miguel de las Victorias en 1703, lector de Prima, tal vez en La Palma, donde moraba en 1709, juez para la ejecución de los mandatos en 1725, lector jubilado y comisario de la Orden Tercera, entre los años 1726-1727, en Santa Cruz de La Palma, y definidor provincial entre 1739 y 1742 . De ser concretamente este fraile, habría tomado el hábito el 16-IX-1686 en el convento de San Miguel de las Victorias de La Laguna, siendo sus padres Juan Rodríguez del Cabo y María Sidrón, naturales de La Orotava, lo cual casa con lo que dice Juan de San Antonio en su Bibliotheca Vniversa Franciscana (t. I, Matriti, ex typographia Causae V. Matris de Agreda, 1732 [republished by Gregg Press Limited, England, 1966] 329 b, sobre su nacimiento, dando noticia además de otra obra suya. Dice así: «Emmanuel Fernandez Sidron, ex Oppido Orataba (sic) Insulae Tenerifensis, Lector Jubilatus Prov. Canariensis S. didaci Regul. Observant. opus egregium exaravit Hispanico idiomate, nempe: Expositionem Epistolarum $S$. Francisci de Paula ad Petrum de Limena. Est opus eruditissimum, quod penes se habuit Author anno 1728 \& inscribi potest Expositio Apocalypsis; fere enim librum integrum Apocalypsis interpretatur. Ex relatu laudatae Provinciae».

13 Ibidem, p. 880. 
De regreso a la isla de La Palma, supo de la existencia y buena acogida de estas obras del benedictino, «remitidas a ella (quizá para cantaletearme, según tengo noticia) por un cierto cavallero, criticón de Tenerife, que quiere apostar en lo satyrico con Juvenal, en lo poético con Quevedo y en lo engañoso con Theodisco» ${ }^{14}$. La insistencia de un paisano suyo («un bonete, ingenio de esta isla, no de los de borla, sino de los de burla, porque de todo se ríe y sobre todos quiere nadar, porque intenta hazerse de corcha haviéndolo hecho Dios zerne»15) fue la que dio lugar a la realización de la Carta apologética. Este personaje, que no tenía empacho de zaherir algunas autoridades tenidas en gran consideración por Sidrón, hizo que nuestro fraile se aprestara en conseguir el tomo segundo del Teatro Universal -el que más al caso le venía- para meterse de lleno en enjuiciar los que considera devaneos del benedictino ante unos hechos que asume sumamente probados.

Pero antes da a entender, claramente, la reticencia de Feijoo a las autoridades, pilar sobre el que va a sustentar su apología, que anticipa un cúmulo de lecturas de uso general por los miembros de la Orden. Así se lee en su parágrafo $5 .^{\circ}$ :

Finalmente, logré haver a mis manos el 2. ${ }^{\circ}$ tomo del M. R. P. Feijoo (que es el que más necessitaba y el que comprehende la materia en que me corrige), y hallé en él tan retratado el genio de su aficionado que más que símil me parecía original. Mi amigo, en el R. Feijoo registré tan al vivo la misma jactancia, las mismas sátyras, las mismas sentencias, tan junto todo con el absoluto discurrir de nuestro yngenio palmense, que no fue otro el que descubrí, mas el mismo. Tan transformado en él que, si huviera muerto nuestro presbítero y no professara yo la philosophía christiana, afirmara con Pithágoras que toda su alma havía transmigrado en el M. R. Feijoo. No se enamoró nuestro clérigo de el padre; enamorose, como Narcisso, de sí mismo, porque se vio retratado en las inquietas aguas de sus ideas, genio y admirable satisfazión. Por esso le pareció águila, porque su merced se tiene por tal. Mucho es que yo, siendo un topo (aunque veinte y nueve años atado a los bancos de el estudio, y diez y seis de éstos en la tarea de la cáthedra, con el concurso de quatro escuelas), haya hallado algo que admirar y mucho que notar en las obras de el M. R. Feijoo. Digo algo que admirar, porque admiro en este tomo su erudición, su mucho allegar de cuentos y chistes, las antiguas y exquisitas noticias que acarrea la diversidad de opiniones que refiere, y los infinitos autores que cita (aunque de pocos da el lugar, porque debe de ser moda también). Bien que de todo esto están las librerías y los libros, aun de las Islas, colmados, ¿quánto más lo estarán las de nuestra España y Euro-

${ }^{14}$ M. Fernández Sidrón, «Preludios», en Carta Apologética en que se defienden las Cartas de el Gran Padre San Francisco de Paula, las profecías de San Malaquías, arzobispo, y los oráculos de las Sibylas, contra la opinión de el M. R. P. Fr. Benito Gerónimo Feijoo, Maestro General Abad y Monge Benedictino, 1735, f. $1 \mathrm{v}$.

${ }^{15}$ M. FERNÁNDEZ SidRón, «Preludios», en Carta apologética..., fol. 1v. Sobre la personalidad del caballero y del fraile, sugiere E. Benito Ruano (ibidem, 309-310) que se trate, respectivamente, de Cristóbal del Hoyo Solórzano, marqués de la villa de San Andrés y vizconde de Buen Paso, y del religioso fray Juan de Leyva.

Hispania Sacra, LXI

124, julio-diciembre 2009, 621-647, ISSN: 0018-215-X 
pa? Noto que él es un hombre a quien San Augustín no satisfaze, con quien el B. Alberto Magno es un sensillo y aquel gran maestro de la philosophía natural e investigador de sus ocultos secretos, el Padre Eusebio Nieremberg, es enano, cito credente, y ambos con Aristóteles fáciles en trasladar. En no conviniendo con su opinión y dureza de filosófica fe, todas las historias son falsas, todos los autores mentirosos y todas las noticias fábulas. Feliz España y venturosa Oviedo, que iluminas el mundo con un Sol, en cuya comparación son sombras las mayores lumbreras de la Yglesia. Punto y jadmiración!, que el interrogante quedará para otro $\mathrm{caso}^{16}$.

Este alegato deja entrever desde ahora el carácter conservador que tiene el manuscrito de Fernández Sidrón. Da cuenta así de la dificultad que tuvieron para cuajar en la sociedad del momento las nuevas formas de pensar, ejemplificadas en este caso en la persona del benedictino. Derivado de ello, seguramente, es la presencia de tantos escritores y obras que citados en los márgenes, aunque éstos, bien mirado, pueden verse como reflejo claro de la pervivencia del método escolástico, criticado duramente por el propio Feijoo ${ }^{17}$.

En efecto, este modelo pedagógico pervive incluso en años posteriores al momento en que se fecha el texto de M. Fernández Sidrón, y el ejemplo más evidente lo encontramos en uno de los consagrados escritores del siglo XVIII, citado anteriormente, José de Viera y Clavijo. En su faceta de discente, en concreto en sus estudios de Teología y Filosofía, todavía hubo de soportar las incomodidades de aquel método, muy común en los que aspiraban a profesar en las órdenes religiosas del momento; sin embargo, como apunta V. Galván González, «esta primera educación no dejó grandes huellas en su espíritu y contra ella luchará desde sus escritos, adoptando una posición antiescolástica, de acuerdo con una corriente muy en boga a lo largo de la centuria» ${ }^{18}$.

\footnotetext{
${ }^{16}$ M. FERnÁNDEZ SidRÓN, «Preludios», en Carta apologética ..., f. 2 v.

${ }^{17}$ En Teatro Crítico Universal, o Discursos varios en todo géneros de materias, para desengaño de errores comunes; escrito por el Muy Ilustre Señor D. Fr. Benito Gerónymo Feyjoo y Montenegro, Maestro General del Orden de San Benito, del Consejo de S. M. \& c., tomo VIII, «Abusos de las Disputas Verbales. Discurso Primero», §. 1, Madrid, MDCLXXIII, pp. 1-2. Como en el caso de la Carta apologética, en la cita de este texto se respeta la ortografía del texto, y sólo se actualiza la puntuación y acentuación.

18 V. Galván GonZÁlez, La obra literaria de Viera y Clavijo, Las Palmas de Gran Canaria, 1999, p. 22. S. DE LA NUEZ, «Viera y Clavijo, poeta ilustrado», Anales de Literatura Española, 2 (1983), 159, manifiesta que, en esta primera etapa de su formación, «es cuando se pone en contacto con las obras francesas de los enciclopedistas que entraban clandestinamente por el Puerto de la Cruz, leyendo, al mismo tiempo, la obra del fraile racionalista Jerónimo Benito Feijoo, cuya lectura, como él mismo confiesa, fue 'como una ráfaga de feliz claridad', en medio 'de la lóbrega noche' de la escolástica» (Tomo esta referencia en V. GALVÁN GoNZÁLEZ, «Los géneros cultivados por Viera y Clavijo», en Y. ARENCIBIA-R. FernÁNDEZ HERNÁNDEZ, (eds.), Historia crítica. Literatura canaria, vol. 2. Siglo XVIII, Las Palmas de Gran Canaria, 2003, 222). A. CioRANESCU («Introducción», a J. de Viera y Clavijo, Noticias de la Historia General de las Islas Canarias, t. I, Santa Cruz de Tenerife, 1982, p. XX) refiere asimismo: «Hizo sus estudios en el convento dominico de La Orotava. Nada sabemos de estos estudios,
} 


\section{LA CARTA APOLOGÉTICA Y EL CONTEXTO DE LA ÉPOCA}

Visto lo anterior, se entiende que el texto haya que incluirlo dentro de las polémicas que se generaron a raíz de la publicación de las obra feijoniana, en el cual abunda una acusada hostilidad hacia el benedictino, muerto en Oviedo el 26 de diciembre de 1764, y concretamente hacia su Teatro universal.

Ciertamente, uno de los acontecimientos que más se destaca a comienzos del siglo XVIII, como anticipo de esa apertura a nuevas formas de entendimiento, marcada esencialmente por el cultivo de la razón, es la entrada en escena -de forma aparentemente abrupta- del fraile benedictino Benito Jerónimo Feijoo y Montenegro ${ }^{19}$. Mucho se ha escrito de este autor y del significado de su obra $^{20}$, de lo cual no se va a hablar aquí para no abultar en exceso este trabajo. Sí parece asentado que la obra del benedictino oscilaba, usando las palabras de Giovanni Stiffoni, «entre un cauteloso rechazo de la tradición del Barroco español y un reconocimiento a medias de los valores de la moderna cultura europea» ${ }^{21}$. También se ha considerado la obra de Feijoo no como el resultado de un momento concreto, sino de unos condicionantes que propiciaron su gestación y que facilitaron un público favorable a las ideas expresadas allí. En todo ello tuvieron gran responsabilidad los llamados «novatores».

Sin embargo, no todos estuvieron de acuerdo con este nuevo espíritu y los renovadores aires que traía. Ese inmovilismo y la pertinaz sumisión a determi-

salvo cuanto él mismo refiere que llegó a lucirse en las tesis de filosofía. Lo dice muy tarde, y con cierta guasa, porque cuando lo dice, poco le queda de los recuerdos de aquella filosofía escolástica, cordialmente aborrecida después».

${ }_{19}$ Así lo indica J. M. CASo GonZÁleZ, «Temas y problemas de la literatura dieciochesca», en F. Rico, Historia y crítica de la literatura española. IV. Ilustración y Neoclasicismo, Barcelona, p. 10. Desde temprano encontramos referencias biográficas sobre el benedictino y su obra (véase A. MiLLARES CARLO, «Prólogo», a Feijoo, Teatro crítico universal, Madrid, 1923, pp. 9-10) en la Oración fúnebre en las exequias que en 22 de enero de 1765 celebró el Real Monasterio de San Julián de Samos a su hijo fray Benito Feijoo (Madrid, Manuel Martín, 1765) del P. Noboa; en la Breve exposición del grave sentimiento con que el Real Colegio de San Vicente de Oviedo... lamentó la muerte del ilustrísimo señor don fray Benito Jerónimo de Feijoo (Salamanca, Imprenta de Antonio Villagordo y Alcaraz, 1764) y en la Oración fúnebre que en las solemnes exequias que la Universidad de Oviedo consagró en el día 27 de noviembre de este año de 1764 a la inmortal memoria del ilustrísimo y reverendísimo señor don fray Benito Jerónimo Feijoo y Montenegro... dixo el señor don Alonso Francos Arango (Oviedo, por Francisco Díaz Pedregal. Año de 1765). Por lo demás, es recomendable la Bibliografía de J. M. Caso González y S. Cerra Suárez, en B. J. Feisoo, Obras completas, t. I, Colección de Autores Españoles del siglo XVIII, 1-I, Oviedo, 1981. Para bibliografía posterior a 1980 (a partir de junio de 1986) véanse los números correspondientes al Boletín del Centro de Estudios del Siglo XVIII. Bibliografía dieciochista, Universidad de Oviedo, Cátedra Feijoo.

${ }^{20}$ Cfr. también I. URZAInKI (ed.), Feijoo, hoy, Fundación Gregorio Marañón-Instituto Feijoo de Estudios del Siglo XVIII, Oviedo, 2003.

${ }^{21}$ G. STIFFONI, «La cultura española entre el Barroco y la Ilustración (circa 1680-1759)», en Historia de España Menéndez. Pidal, t. XXIX. La época de los primeros Borbones, vol. II, Madrid, 1995, p. 84.

Hispania Sacra, LXI

124, julio-diciembre 2009, 621-647, ISSN: 0018-215-X 
nadas costumbres heredadas, de díficil erradicación, y contrario a toda nueva forma de ver la realidad y el mundo cultural, no hacen sino reabrir un viejo tópico, heredado de la Antigüedad, la lucha de antiguos contra modernos ${ }^{22}$, algo que parece ya un lugar común a muchas etapas históricas. De esta manera, surgió toda una pléyade de defensores y detractores del benedictino, cuya relación, más o menos exhaustiva, nos descubre A. Millares Carlo ${ }^{23}$. Si pronto las mentes más abiertas le prestaron buena acogida, a muchos otros la obra del benedictino ovetense les produciría más de un escozor.

Hasta la Islas llegó el maremoto feijoniano ${ }^{24}$, y un claro ejemplo es esta Carta apológetica de Fernández Sidrón, incluida, como se puede pensar, en el grupo de los críticos.

\section{EL ESTILO DE LA CARTA}

Este carácter, unido al sistema pedagógico en el que formó nuestro franciscano, lleva a considerar de inmediato (lo que sucede realmente) que la Carta apologética pueda dar muestra de los esquemas aprendidos en la disputa esco-

\footnotetext{
${ }^{22}$ Cfr. sobre este tópico, E. R. CunTius, Literatura europea y Edad Media Latina, trad. de M. Frenk Alatorre y A. Alatorre, vol. I, Madrid, 1984, $4^{a}$ reimpr., pp. 354-360. También, J. A. MARAVALL, Antiguos y modernos. Visión de la historia e idea de progreso hasta el Renacimiento, Alianza Editorial, Madrid, 1986, p. 93, ha incidido en la reacción que provoca toda novedad. Así comenta: «Si es de lejano origen la inclinación a la novedad en la cultura europea y remonta a las fuentes misma de las que ésta brota, también ha sido amplia y reiterada la posición contraria. Es una actitud frecuente de la psicología humana -mas fuerte en unas épocas que en otras- la de considerar la apetencia de cambios innovadores como cosa de gentes bajas y más bien ignorantes. Hay como una tendencia constante a tachar de aventureros y amigos irresponsables de toda novedad a cuantos se oponen a un orden social existente o que, impuesto desde fuera, trata de ser defendido por sus partidarios como expresión del legítimo y normal estado de las cosas».

${ }^{23}$ Figura como «Apéndice» y es, como indica, una «Enumeración de las obras que se publicaron en pro y en contra del Teatro crítico y Cartas eruditas» (pp. 63-86 de la edición citada en la nota 18 del presente trabajo), donde se repasan los autores que han participado de la polémica en relación con determinados libros o volúmenes de la obra feijoniana. Es de notar que aquí no se cita la Carta apologética de M. FERNÁNDEZ SIDRÓN, seguramente por tratarse de una fecha anterior al Ensayo de una biobibliografía del polígrafo canario, donde ya encontramos referencia a la misma y a nuestro franciscano.

${ }^{24}$ De tal realidad da cuenta M. FERNÁNDEZ SidRón («Preludios» a Carta apologética..., § 1. Ello también se ejemplifica en autores de su época y posteriores. Podemos mencionar aquí a la persona del marqués de San Andrés, «lector apasionado de Feijoo y Bacon» (C. Brito DíAZ, «El vizconde de Buen Paso: prosa y poesía», en Y. ARENCIBIA-R. FERNÁNDEZ HERNÁNDEZ, op. cit., p. 172) o a Juan Antonio de Urtusáustegui (M. HeRnÁNDEZ GonZÁLEZ, «Los memorialistas canarios del siglo XVIII», en Y. ARENCIBIA-R. FERNÁNDEZ HERNÁNDEZ, op . cit., p. 69), los cuales podrían verse acompañados de otras muchas figuras, conocidas o anónimas, que no hicieron ascuas a la obra del ovetense. Incide, además, en la influencia de Feijoo y en las circunstancias que favorecieron la expansión de la doctrina del benedictino de manera general, Y. ARENCIBIA, «Temas y problemas de la literatura del siglo XVIII en Canarias», en Y. ARENCIBIA-R. FERNÁNDEZ HERNÁNDEZ, op. cit., pp. 16-17.
} 
lástica, con unas peculiaridades que, tanto en la forma como en el fondo, participan de las características propias de los escritos que Feijoo quiso desterrar ${ }^{25}$.

Desde el mismo «introito», el insoslayable prólogo admonitorio al lector, Fernández Sidrón intenta atraer a sus propios congéneres, sus «payzanos», manifestando el deseo de que sean ellos los destinatarios de su obra, escrita a este fin en lenguaje provincial. A ellos también se volverá a referir en el parágrafo 156. Entendido esto así, la obra es claro ejemplo del castellano y del latín de aquellos momentos (aunque bien pudiera entenderse esto al revés, y ser otra vez evidencia de viejos tópicos ${ }^{26}$ ).

Se percibe, de este modo, en muchas partes de la Carta apologética, que el autor introduce en su discurso expresiones latinas típicas de la escolástica ${ }^{27}$. Muchas veces ni siquiera las pone en cursiva, lo cual pudiera llevarnos a considerar el grado de cohesión que existía, para determinados géneros, entre las lengua latina y castellana. En otras ocasiones, esas expresiones y frases, esta vez en castellano, tienen claras reminiscencias formales del latín escolástico. No son extrañas, pues, proposiciones como la del Parágrafo 238, donde se dice:

« ¿Está, sin duda, concluyente esta gran demonstración! Mas ¿en qué materia y figura? ¿En quál de las dos premisas se contiene la mayor extremidad que sale por subjecto en la consequencia?».

\footnotetext{
${ }^{25}$ Así lo pone de relieve A. Millares CARLo («Prólogo», a Feijoo, op. cit., pp. 46-47) al comentar algunos discursos del Teatro crítico en los que Feijoo se lamentaba del retraso de la enseñanza (en concreto, en el Tomo VIII, Discursos: 1. «Abusos de las Disputas Verbales»; 4. «Argumentos de Autoridad» y 8. «Examen Filosófico de un suceso peregrino de estos tiempos»). Dice así: «La experiencia adquirida en sus años de estudiante y de maestro le llevó a combatir el abuso de las disputas verbales en las aulas, y ese excesivo amor de la propia opinión que antes de confesar noblemente el error, prefiere echar mano de toda clase de sofismas para persistir en él. Los argumentos de autoridad no tienen a sus ojos ningún valor en la esfera de las cosas científicas. 'Por grandes, por eminentes -escribe-, por sublimes que sean o hayan sido la doctrina y santidad de los escritores..., no por eso se ha de tener por cierto lo que hayan escrito. Será, por consiguiente, lícito apartarse de su sentir en una u otra cosa cuando la razón nos persuade lo contrario'».

${ }^{26}$ En efecto, si esto se entiende sensu contrario, como velada censura, la Carta apologética sería reflejo de la diversidad y los muchos errores que se cometían en la lengua castellana en los variados documentos de la época; porque, bien mirado, la obra no abunda en coloquialismos, más bien escasea, dejando de lado la ortografía, que se puede ver en los textos que transcribimos de la misma. Sin embargo, a poco que ahondemos, lo que en apariencia pretende ser una declaración sin más de intenciones, esconde una de las variantes del tópico, heredado de la Antigüedad, de la «falsa modestia». En concreto, las palabras de nuestro franciscano encajan, en este caso, con una de las fórmulas prefijadas al respecto, como era decir que se usaba una lengua inculta y grosera (rusticitas), como lo hace, por ejemplo, Tácito en su Agrícola o Garcilaso de la Vega en su Égloga III. Cfr. E. R. CurTIUS, op. cit., p. 128.

${ }^{27}$ Así, como ejemplo, el Parágrafo 119 dice: «que es el absolute prohibido»; el parágrafo 120: «y lo creo libenter»; y en el 220: «philósopho mere especulativo».
}

Hispania Sacra, LXI

124, julio-diciembre 2009, 621-647, ISSN: 0018-215-X 
Pero más que nada, esta obra se caracteriza por el principio de autoridad, como sucede en otras muchas de la época. Recordemos que en sus Contextos y discursos, tal y como vimos antes, ofrece una relación de las autoridades consultadas $^{28}$. No es extrañar, pues, que plantee la argumentación de su apología bajo los principios de la diatriba, es decir, como respuesta argumentada que se fundamenta sobre determinados autores (esto es, sobre su auctoritas) considerados dentro de ese método como modelos a seguir y receptáculos de la verdad. Hay que insistir en que esta práctica era común y continua en el quehacer de muchas personas pertenecientes a órdenes religiosas educadas al cobijo de las rutinas de aquella escuela ${ }^{29}$. Ocurrió en todo momento y en diferentes lugares. Ante la escasez de datos en las Islas, encontramos referencias muy concretas en otros sitios, que permiten comprender el uso que hacían de los libros desde temprano los miembros de la Orden.

El método en el que se formaban los franciscanos, aunque ello no exclusivo de esta Orden, preveía un cúmulo de lecturas cuya función trascendía propiamente la formación intelectual de la persona, ampliándolo a otros ámbitos como el de la enseñanza. En este sentido y como ejemplo, vienen bien las palabras de I. Vázquez Janeiro cuando refiere la aplicación que se hacía de los li-

${ }_{28}$ Parece ser práctica común, como sucede con Cristóbal Pérez del Cristo, quien en el capítulo segundo de Excelencias y antigüedades (Jérez de la Frontera, 1679) ofrece una exhaustiva relación de autores y obras. Cabe observar que éste es uno de los pocos escritores de las Islas mencionados en la Carta apologética.

${ }^{29}$ La propia preparación, que empezaba en las aulas conventuales, obligaba a los alumnos a tejer una infinidad de razonamientos, mejores o peores, que se multiplicaban luego con otros hasta llegar a extremos insospechados, pero que no ofrecían una solución clara. De este sistema se queja Feijoo en su Teatro..., t. VIII, «Dictado de las Aulas. Discurso Tercero», §. I, 3, pp. 31-32: «Lo peor es, que no hay sugetos menos capaces de poner término a las cavilaciones escolásticas que los que presumen poder ponerle. Necesariamente han de ser de cortísimo ingenio los que no perciben que esto es lo mismo que detener el curso de un río o poner puertas al campo. Lo que, pues, suelen lograr con sus prolixas tareas es llenar grandes volúmenes de soluciones y réplicas, que, amontonadas unas sobre otras, hacen una ostentosa perspectiva; pero toda esa máquina se viene al suelo con un papirote solo de un discurso claro: y es el caso, que freqüentemente se funda todo en una proposición mal entendida, por equívoca o por obscura; y aclarada, u distinguida aquella proposión (sic), ya no son del caso treinta o quarenta hojas de cartapacio que se fundaron en aquel ruinoso cimiento. Quántas veces el profesor da por cierta la mayor de un sylogismo y, dexándola aparte, como innegable, gasta mucho tiempo y papel en probar la menor; pero después, examinadas una y otra premisa por ojos más perspicaces, se descubre que en la mayor está el defecto y para ella no hay prueba alguna en el abultadísimo cartapacio. Dígolo porque lo he notado muchas veces; y no pocas me sucedió tronchar un argumento (absit verbo jactantia) que se me proponía como indisoluble, sólo con manifestar la ambigüedad de alguna proposión (sic), en que el arguyente no havía reparado; y así tenía puesta toda la artillería de las pruebas acia otra parte. Así estos argumentos, que 1laman Aquiles, suelen tener la suerte de aquel héroe griego, de quien les vino el nombre, que por un talón, esto es, por una pequeña y descuidada parte de su cuerpo, siendo invulnerables en todo el resto, viene la flecha que los derriba». 
bros, que provenía de época medieval, y algunos autores consagrados en determinadas disciplinas:

Los libros que los frailes recibían... no eran sólo para fines de adquirir una instrucción personal fuese científica o espiritual; eran también, y sobre todo, para capacitarse en vistas a poder enseñar a los demás. [...] Según los niveles de estudios realizados, el alumno salía de las aulas bachiller, licenciado o doctor y maestro. No es del caso describir aquí todos los requisitos previos que cada título exigía según las diversas facultades; recordaré sólo, porque nos interesan, algunos conceptos más elementales: en filosofía se exponían los libros de Aristóteles y se obtenía el bachillerato después de tres años; en teología los textos fundamentales eran la Biblia y los cuatro libros de las Sentencias; el método comprendía la lectio, la disputatio y la praedicatio, y el bachillerato se obtenía después de siete años ${ }^{30}$.

Esas lecturas, que se acrecentarían paulatinamente, conformaron un bagaje cultural del que difícilmente iban a desprenderse los adeptos al sistema. En muchas partes aparecen huella de esto, una de las cuales son los márgenes de algunas obras.

\section{LOS MARGINALIA DE LA CARTA APOLOGÉTICA: NATURALEZA DE LAS CITAS}

Varios rasgos confieren peculiaridad, de manera general, a los marginalia. Como apuntaba C. Codoñer, «a través de su estudio podemos ir reconstruyendo a manera de un mosaico el mundo de intereses de su autor, sus lecturas dominantes, el destino que piensa otorgar a sus anotaciones y, en consecuencia, el modo de proyectar sus lecturas, junto al modo de leer» ${ }^{31}$.

$\mathrm{Y}$, en efecto, van a ser esas lecturas (quizás el término «dominante» aquí no sea el apropiado) las que se agolpen en los márgenes del manuscrito sidroniano; en ello, antes se dieron algunos datos, tuvo mucho que ver el método de enseñanza que conformó los años de aprendizaje de nuestro autor: menciones, particularmente, a la Biblia, pero también, juntamente, la existencia de todo un arsenal de nombres de escritores de diversas épocas, de géneros también diversos, sobre los cuales giraba entonces la ciencia conocida. Serán muchos de estos autores (en general, sobre el concepto de auctoritas) contra los que arremeta el

30 I. VÁZQUEZ JANEIRO, «Los estudios franciscanos medievales en España», en Espiritualidad y Franciscanismo: VI Semana de Estudios Medievales, La Rioja, 1996, p. 49.

31 C. Codoñer, «El diálogo con los textos de Hernán Núñez de Guzmán», en J. M. ${ }^{a}$ MaEstre Maestre-J. Pascual Barea-L. Charlo Brea (eds.), Humanismo y Pervivencia del Mundo Clásico. Homenaje al Profesor Antonio Fontán, III.2, 2002, pp. 856-857.

Hispania Sacra, LXI

124, julio-diciembre 2009, 621-647, ISSN: 0018-215-X 
fraile benedictino, incidiendo en la pronta deificación que se hace a determinados personajes que, en vida, no tuvieron la fortuna de verse ni siquiera conside$\operatorname{rados}^{32}$.

A ello se refiere el propio Sidrón en el parágrafo 5, aduciendo el poco afecto que el fraile de Oviedo sentía por determinadas autoridades, representadas en este caso en los nombres de San Alberto Magno, el padre Eusebio Nieremberg y Aristóteles, autor que, como se sabe, se constituyó en pilar fundamental sobre el que se apoyarán los escolásticos desde sus antecedentes inmediatos, el final de la patrística; sería en el apogeo de la escolástica, coincidente con el siglo XIII, cuando el filósofo griego fue asimilado especialmente por las órdenes religiosas franciscana y dominica, cuyos frailes constituirán la cantera de filósofos y teólogos del momento.

Por lo demás, lo normal es que estas anotaciones -como puede comprobarse sólo con echar un vistazo al texto de la Carta apologética- sirvan para asentar las afirmaciones del autor, como ocurre con otras obras de tono parecido, escritas en las Islas ${ }^{33}$. Sin embargo, cabe diferenciar el procedimiento de nuestro franciscano, para quien era algo habitual, de lo que ocurre en otros escritos,

32 Teatro..., t. VIII, «Argumentos de Autoridad. Discurso Quarto», §. I-II, pp. 41-43.

${ }_{33}$ Uno de los autores estudiados con cierta justeza, del cual hace mención por su gravedad el propio M. Fernández Sidrón, es fray Andrés de Abreu. Se han descrito variedad de fuentes usadas por este autor en la composición de su biografía de San Francisco (cfr. J. DíAZ ARMAS, «Introducción» a F. Andrés de Abreu, Vida de San Francisco, La Laguna, 2000, pp. 87-93), apuntándose que las preferencias de este autor suelen ser, en vez de las obras hagiográficas antiguas de Tomás de Celano o San Buenaventura, otras amplificaciones posteriores que tienen materiales mas interesantes (caso de la Leyenda de los tres compañeros, la Leyenda de Perusa, el Speculum Perfectionis o las Fioretti di San Francesco). También se rastrea la presencia de las compilaciones de Waddingo (Annales Minorum), la Crónica seráfica de Cornejo (autor de las primeras cuatro partes), la Natura Prodigium de Pedro de Alba (Madrid, 1651), o de autores como San Buenaventura (el «Doctor Seráfico), Bartolomé de Pisa, Juanetín Niño o Juan de Soria Buitrón y su Epílogo de la vida, muerte y milagros del serafín llagado y singularíssimo patriarca San Francisco (Cuenca, 1649). Otras muchas obras y escritores de procedencia diversa se agolpan, asimismo, en los márgenes de otra pieza menos conocida de este franciscano, una censura en latín realizada contra la obra titulada El Christiano interior (Madrid, por Francisco Sanz, 1677). Aquí, dejando de lado los diversos libros de la Biblia, aparecen San Agustín, San Alberto Magno, Ademanus, Diego Álvarez, San Ambrosio, San Anselmo, Santo Tomás de Aquino, Pedro de Aragón, Dionisio Areopagita, Juan Azor, Beda, Martín Becan, San Bernardino de Siena, San Bernardo, San Buenaventura, César Baronio, Ambrosio Calepino, Juan Calvino, Juan de Cartagena, Francisco del Castillo y Velasco, Alfonso de Castro, San Cayetano de Thiene, San Juan Crisóstomo, Cristóbal Delgadillo, Antonino Diana, Fenelon, François Genet, Jean Baptiste Gonet, San Gregorio, Andrés de Guadalupe, San Hilario, Gilbertus de Hoylandia, Lactancio, Cornelio a Lapide, León XI, Franciscus Lichetus, José López Ezquerra, Ignacio Lobo, Bartolomé Medina, el abad Ruperto, J. Duns Scoto, Francisco Suárez, Francisco de Toledo, amén de otras citas indirectas (cfr. F. SALAS SALGAdo, «Las notas de la censura latina...», 138-154). 
donde esta práctica podía ser tenida como un mero alarde decorativo ${ }^{34} \mathrm{o}$ una simple muestra de erudición ${ }^{35}$.

En estas citas la referencia es precisa, con información, la mayoría de las veces, de autor y obra, seguido de capítulo, si lo hubiere, y foliación o paginación, al contrario de lo que ocurre en el texto donde, por lo general, sólo hay mención nominal ${ }^{36}$.

Dado el carácter inacabado que parece tener el escrito sidroniano, hay que pensar de inmediato en una labor gradual en la redacción del mismo, lo cual facilita a su autor la inclusión en los márgenes de referencias en favor o en contra de los argumentos aducidos, conforme, seguramente, consultaba nuevas obras.

Por la disposición y referencias que se dan, cabe considerar la consulta directa de algunos textos por parte de nuestro fraile, si bien no hay que obviar que pudiera haber recurrido a las frecuentes misceláneas que existían en la época.

Característica también es la cita indirecta, donde un autor u obra, o ambos a la vez, se citan a partir de otro autor. Ejemplo de esta clase de cita, lo ofrece las hagiografías del escritor alemán Lorenzo Surio (1522-1578), autor que ordenó las vidas de los santos publicada por Lippomani, corrigiendo estilo, eliminando

34 Así se considera la abundancia de citas latinas que aparecen en los sermones, ejemplos claros de la oratoria sagrada de aquellos momentos. A propósito de la primera parte del exordio de un sermón dedicado a Santa Isabel de Hungría, debido al fraile Francisco Soto y Marne, apunta F. Sánchez Blanco (La prosa del Siglo XVIII, Madrid, 1992, p. 80): «Salta a la vista que el sermón no tiene por fin catequizar o enseñar a los asistentes al acto sagrado. La profusión de citas latinas son pura música, vacía de contenido, para un público en su mayoría analfabeto. Pero incluso para aquellos que sabían algo de latín debieron quedarse en ayunas acerca de lo que Soto y Marne quería explicar y probar con la metáfora de la margarita/perla».

35 Es el caso del marqués de San Andrés, Cristóbal del Hoyo Solorzano y Sotomayor, cuya obra Madrid por dentro abunda en citas eruditas mayormente en latín. Cfr. a este respecto, lo que comenta A. Cioranescu, «Introducción» a Cristóbal del Hoyo Solórzano y Sotomayor, Madrid por dentro (1742), Santa Cruz de Tenerife, 1983, pp. 27-32. En este sentido, para una ideal global de la presencia de la cultura y los autores clásicos en este autor, véase F. SALAS SALGADO, «Cristóbal del Hoyo, aristócrata, libertino y humanista», en J. M. ${ }^{a}$ Maestre Maestre-J. Pascual Barea (coords.), Actas del I Simposio sobre Humanismo y pervivencia del Mundo clásico, vol. I.2, 1993, 977-984.

${ }^{36}$ Aparte de los que ya se han mencionado, cabe citar, entre otros, a San Augustín, Lactancio Firmiano, S. Crispín Zapatero, S. Duustano Herrero, S. Floro Aserrador, S. Enrique Carnicero, su venerable y subtilíssimo Maestro, el Angélico Doctor (Santo Tomás de Aquino), Cayetano, Bartolomé de Medina, Suárez, Valencia, Christóbal de Castro, León de Castro, Martín Martínez, Hurtado, Alarcón, S. Justino, S. Irineo, Tertuliano, Cornelio a Lapide, Orígenes, Clemente Alexandrino, S. Hipólito, S. Crisóstomo, S. Gregorio Papa, Sulpicio Severo, Theodorico, Procopio, el abad Ruperto. Otro grupo lo conforman, en fin, S. Jerónimo, Orígenes, S. Ambrosio, el venerable abad floriacense Joaquín de Fiore, Bartolomé de Pisa o S. Domingo de Guzmán. Algunos de ellos, como puede comprobar en el «Apéndice», aparecen también en los marginalia sidronianos.

Hispania Sacra, LXI

124, julio-diciembre 2009, 621-647, ISSN: 0018-215-X 
algunas biografías y añadiendo otras nuevas, para evitar la crítica de los protestantes, confeccionando así un texto que elogiaron sus contemporáneos por su fidelidad y exactitud, y que, como se ve, se mantuvo vigente.

\section{LA DIVERSIDAD DE AVCTORES Y LA VIGENCIA DEL LATÍN}

Aparte de las diversas menciones nominales, en algún parágrafo de la Carta se viene a caracterizar la diversa procedencia y condición de las autoridades. Concretamente, en el parágrafo 15 nuestro franciscano subraya la importancia y validez de unos «hombres muy racionales y de grandes experiencias, sobre ser unos santos, otros, varones piadosos y venerables, y todos, grandes lógicos, philósophos, theólogos y historiadores», pero también «infinitos santos de oficios militares, liberales artes y mecánicas».

De esta manera, el propio franciscano viene a establecer una clara diferenciación entre los auctores prescritos por la Iglesia y aquellos con los que necesariamente puede diferir nuestro autor, pero «que dan notable fuerza y autoridad a la opinión, si la prueban y la siguen». Y muchas de las obras que salieron de la pluma de estas autoridades, si no todas, como se puede comprobar luego, fueron escritas en la lengua que todavía en ese momento tenía una vitalidad importante, el latín ${ }^{37}$.

Esta circunstancia, que puede considerarse hasta banal en estos momentos, tiene especial interés, pues viene a corroborar la vigencia de esta lengua, no sólo por tratarse del medio en que comúnmente se expresaban los que pertenecían a la religión católica, sino por ser el cauce en el que se difundía la ciencia del momento.

Evidentemente, dada la naturaleza del texto sidroniano y los diversos capítulos de que consta, es lógico que aparezcan sólo determinados autores, y seguro que no los más importantes. Las carencias en este sentido deben también ser tenidas muy en cuenta, ya que es probable (si no seguro) que fueron algunas más las obras que ocupaban los anaqueles de las bibliotecas conventuales frecuentadas por nuestro franciscano, algunas de uso común entre los escritores de la Orden desde época temprana. La perceptible abundancia (lógica, por otra parte) de textos sagrados y comentarios bíblicos no quita para que debamos mencionar algunos escritores que, aunque no aparezcan en el repertorio marginal sidroniano, tenían entonces gran aceptación. Es el caso de Dionisio Aeropagita,

${ }^{37}$ La participación de los franciscanos en la reforma educativa de la época, y especialmente en la erección de una escuela de latinidad en el siglo XVIII, puede verse en J. L. SANTONJA CARdONA, «Enseñanza y reforma educativa en Alcoi e Ibi durante el siglo XVIII», Revista de historia moderna: Anales de la Universidad de Alicante, 20 (2002), 375-396. 
Boecio o Casiodoro; el propio Aristóteles (mencionado sólo en el cuerpo de la Carta); Ptolomeo y algunos escritores de filosofía árabes, u otros, como Pedro Lombardo ${ }^{38}$.

También al hilo de aquella reflexión, debiera considerarse la muchas veces reiterada lejanía de estas Islas, causa no sólo de la escasez de material libresco, sino sobre todo de su adecuación temporal. Pudiera ser evidencia de esto la existencia de algunas obras, como la Biblioteca de Sixto de Siena, algo anticuada para el momento frente a otros repertorios bibliográficos, pero cuya mención se deba más a la falta de otros materiales que a un posible olvido (aunque no se puede olvidar el prestigio y la influencia que había tenido este autor en otros órdenes en territorio hispano en épocas anteriores, sobre todo, a partir de la segunda mitad del siglo XVI, en las universidades de Salamanca y Alcalá). Pero, ante las diversas hipótesis que se puedan hacer al respecto, creo que los textos citados en los márgenes de la Carta apologética son suficientes para tener una idea, a falta de otros documentos, de las herramientas bibliográficas con que contaban los miembros de la Orden, ejemplo, además, de esa época entre siglos.

En otro orden de cosas, si algo caracteriza estas citas de los marginalia sidronianos es la variedad, aunque se tenga que insistir en el carácter parcial de la misma.

Tal variedad parece ser común en la orden franciscana desde fecha temprana, pues, como apuntaba A. Rucquoi,

«[...] las lecturas de los frayles mezclaban obras ortodoxas y autores heterodoxos. En las que recomendaban Pedro de Villa Creces y Lope de Salazar coexistían la Biblia, las reglas y crónicas de San Francisco, las Collationes Patrum y las Institutiones de Casiano, la Scala Paradisi de Juan Climaco y obras de y o atribuidas a San Buenaventura, San Jerónimo, San Bernardo, San Gregorio, San Agustín y Santa Clara con las Flores, la Historia Septem tribulationum de Ángel Clareno y obras de «santa» Ángela de Foligno. Por la misma época, en los conventos observantes portugueses estudiados por José Adriano Freitas de Carvalho circulaban, entre otras obras espirituales, la Vita Christi de Ludolfo de Sajonia, el Libro del desprecio del mundo del abad Isaac de Nínive, las Revelaciones de Santa Brígida, el Arbor vitae cricifixae de Ubertino da Casale, los Floretos de Sant Francisco y el Flos Sanctorum. Sabemos también que se leían en Castilla las obras proféticas y milenaristas del médico catalán Arnau de Vilanova -en particular su Vae mundo in centum annis-, de fray Juan de Rocatallada y de Francesc Eiximensis, así como los Vaticinia de summis pontificibus o el Oracullum Cyrilli [...]»39

\footnotetext{
38 Aparecen entre los préstamos de los franciscanos de Compostela. Cfr. para más datos, I. VÁzQUEZ JANEIRO, ibidem, p. 48.

${ }^{39}$ A. RUCQUOI, «Los franciscanos en el Reino de Castilla», en Espiritualidad y Franciscanismo...», p. 83. Esta variedad de autores, géneros y fechas se confirma en los datos que sobre la biblioteca del convento de San Lorenzo de La Orotava ofrece M. HeRnández GonZÁlez (Los conventos de La Orotava, Ediciones Idea, Santa Cruz de Tenerife, 2004, pp. 372-374). De la biblioteca, que debió ser bastan-
}

Hispania Sacra, LXI

124, julio-diciembre 2009, 621-647, ISSN: 0018-215-X 
Pues bien, aquella diversidad de géneros no quita para que abunden más en estos marginalia las referencias a obras de tipo religioso, siendo escasa la mención a autores paganos. Nombra con frecuencia al «libro entre los libros», la Biblia, sobre todo determinadas partes (Ezequiel Deuteronomio, Amos, Corintios, etc); aparecen comentarios, entre ellos, el de San Jerónimo, particarmente su exégesis a determinados textos sagrados; y, como no, obras hagiográficas, como las vida de los santos, citada anteriormente, de Lorenzo Surio.

La variedad afecta también a los autores que compusieron las obras, pues no se circunscriben las citas solamente a autores del momento. Esto se percibe bien entre los comentaristas. Así los textos de autores antiguos, como el mencionado Jerónimo o Beda, quizás en ediciones de la época, conviven con obras de exégetas más cercanos, cuya labor era en muchos casos considerada canónica, como sucede con los jesuitas Francisco de Ribera, Juan de Maldonado o Benito Pereira, pero, sobre todo, el belga Cornelio a Lapide (Cornelis Cornelissen van den Stern), cuyos comentarios tuvieron gran influencia en la predicación y fueron del agrado de otros autores franciscanos radicados en Canarias, como Andrés de $\mathrm{Abreu}^{40}$.

Evidentemente, hay autores que se repiten, como fray Melchor Cano. Su De locis theologicis aparece en varias ocasiones, obra donde estableció las fuentes para la demonstración teológica, a saber, la autoridad de la Sagrada Escritura, la tradición oral, la Iglesia católica, los Concilios, los Padres, la Iglesia romana, los teólogos escolásticos, el valor de la razón natural en materias científicas, la autoridad de los filósofos y la de la historia.

De igual forma, la lectura de los marginalia de la Carta apologética revela otro rasgo significativo, la no adscripción de Fernández Sidrón a obras y escritores sólo de su Orden. Así frente a miembros de la misma sumamente considerados, caso del doctor Sutil, Duns Scoto, personificación de la ciencia franciscana, Bartolomé de Pisa, o, más en su época, Pedro de Alva, es notoria la presencia de escritores de la Compañía de Jesús. Ejemplo de ello es la mención repetidas veces de la obra, Curiosa y oculta filosofía, del escritor ascético español Juan Eusebio Nieremberg. Este escrito, de continuo reeditado, estaba considerado como ejemplo de un género de literatura, bien aceptado entonces, que trataba sobre algunas curiosidades científicas de la época: noticias raras del mundo animal y vegetal, astros o minerales. De raíz aristotélica, tuvo sin embargo influencia del atomismo, asumido luego entre los novatores.

te grande, existen referencias en ciertos inventarios decimonónicos que atestiguan la mixtura de géneros donde se encontraban textos de los Padres de la Iglesia, junto a obras relacionadas con la Medicina, obras edificadoras, diccionarios latinos, obras jurídicas, y algunas obras prohibidas por la Inquisición.

${ }^{40} \mathrm{Cfr}$. F. SALAS SALGADO, «Las notas de la censura latina...», 149 y 155-156. 
Asimismo, la referencia a autoridades paganas, sobre todo autores de la antigüedad clásica, es casi imperceptible. Cuando trata de las Sibilas, cita la traducción de Virgilio por Diego López, trabajo por el que el poeta de Mantua fue conocido prácticamente en el siglo XVII y XVIII ${ }^{41}$, y que constituye una singularidad.

Por otro lado, habría que considerar que el contenido de la obra de Sidrón presupone la aparición de escritos que nada tienen que ver con aspectos religiosos o teológicos. La presencia de obras científicas, extranjeras y nacionales, pudiera ser indicativo de cierta amplitud de miras por parte de nuestro autor. Algunos nombres, como el del geógrafo Abraham Oertel, «Ortelius», autor del Theatrum Orbis terrarum, uno de los primeros atlas modernos, traducido al castellano en 1603, en Amberes, aparecen junto a otros como el del matemático español Jerónimo Cortés, autor del Libro de fisonomía, resumen de los conocimientos de la época en ciencias naturales.

Esta mixtura de géneros, fechas y autores tiene un objetivo evidente: contrarrestar las notorias falsedades que presume nuestro franciscano se encuentran en la obra que censura de Feijoo.

La propia utilización de los textos aducidos y los que luego aparecen en el inventario (evidentemente, no deben entenderse los textos en sí) pueden servir de ejemplo del encasillamiento que un sector grande de la sociedad mostraba a finales del Seiscientos y principios del Setecientos y su reacción ante las novedades. Considérese de este modo la aparición de la obra de Francisco de Palanco, Dialogus physico-theologicus, especie de apéndice que fue de su Cursus philosophicus. Este escrito, entre farragoso y maligno, mostraba la incompatibilidad entre la filosofía de la época y la justificación que se daba de los dogmas católicos desde esta perspectiva. La polémica suscitada llegó, en especial, a los que ya entonces se denominaron novatores, los adeptos a las modernas teorías. Consecuencia de este clima fue la respuesta que dio Jean Sanguens en su Atomismus demonstratus (Toulousse, 1715), traducido luego por Diego Mateo de Zapata y el padre Juan de Náxera en Madrid en 1716.

En definitivas cuentas, cuando España se preparaba para abrirse al mundo ultrapirenaico, con la introducción de un conocimiento más racional (recuérdese que el primer frente antiescolástico se desarrolló desde los años 1680 a 1690, momento en el que se exhumaron, incluso, muchos textos del siglo XVI en donde se combatía la tiranía de esa escuela), todavía había muchos autores afe-

\footnotetext{
${ }^{41}$ Más datos en J. A. IZQuierdo IzQuierdo, Diego López o el virgilianismo español en la escuela del Brocense, Institución Cultural El Brocense, Cáceres, 1989; e ID., «Diego López, traductor de Virgilio: aproximación a un alumno del Brocense», en Actas del VII Congreso Español de Estudios Clásicos, t. III, Madrid, 1989, pp. 543-551.
}

Hispania Sacra, LXI

124, julio-diciembre 2009, 621-647, ISSN: 0018-215-X 
rrados a conceptos y métodos arcanos, cuya pretensión continuista no debe en absoluto ser desdeñada, sino justipreciada en el sentido de que nacen de una realidad, heredera de una tradición.

El franciscano Manuel Fernández Sidrón -por ende, también su Carta apologética (1735)- pertenece a este grupo. Adiestrado, como estaba, en una dialéctica a veces agresiva $\mathrm{y}$, por tanto, dispuesto a «desautorizar» cualquier atisbo de novedad, utilizaba el apoyo doctrinal de unas obras, obsoletas para muchos, que se fueron propagando con el correr de los años, cuya sola referencia ayuda por lo menos a recomponer un universo de libros que de no ser por la aparición en estos marginalia hubieran caído en el olvido.

\section{APÉNDICE}

\section{INVENTARIO}

En el siguiente registro se reproducen las citas que se encuentran en los márgenes de la obra de Fernández Sidrón que sólo contienen referencia a textos y a autores, donde se ha respetado la ortografía del autor, y sólo se actualiza acentuación y puntuación. En versal, de manera ordenada, aparecen los capítulos de la obra donde se encuentran estas citas. Para mayor comodidad, se sigue una numeración correlativa en negrita y paréntesis cuadrados, si bien se respeta la numeración original del texto, que se da también en paréntesis cuadrados, pero en redonda. Se procede luego a la identificación de las obras en cuerpo menor, en las que regularizo la ortografía de los textos latinos a la norma clásica y actualizo la puntuación; lo mismo, hago con los textos en castellano. Cuando hay varias ediciones, relaciono la que se encuentra más cercana a la fecha de redacción de la Carta apologética. Para ello me he servido fundamentalmente del Catálogo de Patrimonio Bibliográfico Español. Sin embargo sintetizo los títulos, reproduciendo lugar, impresor y fecha de impresión. Añado al comienzo, entre paréntesis y negrita, los nombres de autores más desconocidos junto a la fecha de nacimiento y muerte, cuando las he localizado.

\section{PRELUdios} 650.

[1] [Nota 1] Cano de locis Theolog. Lib. 11. ${ }^{\circ}$ De human. Histor. fol. mihi

[(Melchor Cano, O.P, 1509-1560) Reuerendissimi D. Domini Melchioris Cani, episcopi Canariensis, de locis theologicis libri duodecim, Lovanii, sumptibus haeredum Arnoldi Birkmanni, 1569] 
[2] [Al margen] San Gerónimo in praefatione Coment. in Abdiam.

[Sancti Hieronymi operum tomus III, continens commentarius in duodecim Prophetas Minores, Parisiis, apud bibliopolas urbis Parisiensis consortes, 1609]

\section{CRISIS DEL PRÓLOGO}

[3] [Nota 3] D. Greg. Lib. 4. ${ }^{\circ}$ Dialog. et in Homil. 9. ${ }^{\text {a }}$ sup. Ezeq.

[Sancti Gregorii Magni Papae operum tomus tertius, in quo habentur homiliae uigintiduae in Ezechielem prophetam..., Romae, ex typographia Camerae Apostolicae, 1613]

\section{Crisis del $1 .^{\circ}$ Discurso intitulado Guerra[s] Philosóphicas}

[4] [Nota 3] Ita Craanem de homine cap. 90. fol. 532. apud Palanco Dialog. $12 .^{\circ} \mathrm{n} .^{\circ} 109$.

[a) (Teodoro Craanen, $\dagger$ 1668) Tractatus physico-medicus de homine, Neapoli, ex typographia Felicis Mosca, 1722. b) (Francisco Palanco, O. M., 1657-1720) Dialogus physico-theologicus contra philosophiae nouatores, Matriti, ex typis Blasii de Villanueva, 1714]

\section{CRISIS DE El $2 .^{\circ}$ Discurso inTitulado Historia Natural}

[5] [Al margen] Nieremberg Prolusión a la historia natural §. 3. dize que $l a$ servidumbre de Babilonia la pronosticó el parto de una mula. [...]

[(Juan Eusebio Nieremberg, S. J, 1585-1658) Prolusión a la doctrina y historia natural, Madrid, por Andrés de Parra, 1629]

[6] [Al margen] Y de esta opinión es el Padre Nieremberg, Occult. Philos. cap. 83 .

[Curiosa y oculta filosofía, Alcalá, en la imprenta de María Fernández, 1699].

[7] [Nota 4] Cano de Loc. Theolog. Lib. 11. . De human. Hist. cap. 4. ${ }^{\circ}$ [Cf. 1]

[8] [Nota 5] Nieremb. Curios. y oculta Philos. Lib. 4. cap. 4. ${ }^{\circ}$ [Cf. 6]

[9] [Nota 6] Ezech. cap. 27. v. 11. ${ }^{\circ}$

[10] [Nota 7] Hier. in vit. Patr. ${ }^{\text {a }}$. Part. in vita S. Macharij Romani. Invenitur etiam apud Surij Sanctor. die 23. Octob.

[a) Diui Hieronymi Stridoniensis opera omnia, Parisiis, apud Sebastianum Niuellum, 1602. b) (Lorenzo Surio, 1522-1578) De probatis sanctorum historiis, Coloniae Agrippinae, apud Geruinum Calenium et haeredes Quentelios, 1581]

[11] [Nota 8] Pelliz. al Polifemo. Estanc. 7. $§ . ~ 3 .{ }^{\circ}$ Vide al Tostado sobre Euseb. Part. $5^{\text {a }}$. cap. 76. que cita a $S^{\mathrm{n}}$. Aug ${ }^{\mathrm{n}}$, a $\mathrm{S}^{\mathrm{n}}$. Isidoro y a Solino.

[a) (José Pellicer de Salas y Tovar, 1602-1679) Lecciones solemnes a las obras de Don Luis de Góngora y Argote, Madrid, en la Imprenta del Reino, 1630. b) (Alonso Fernández de Madrigal, 1410-1455) El Tostado sobre Eusebio, mineral de letras divinas y humanas en la historia ge- 
neral de todos los tiempos, tomo primero, Madrid, en la oficina de Melchor Sánchez, 1677; tomo segundo, Madrid, Francisco Sanz, 1679]

[12] [Nota 9] Vit. Patr. 2a ${ }^{\text {a }}$ Part. §. CCI. Vide Sol de el Occidente Prelud. 8. cap. 2. ${ }^{\circ}$ n. ${ }^{\circ} 17$.

[(Alonso de San Vítores, O.S.B., 1590- ca. 1660-1) El Sol del Occidente, N. Glorioso padre S. Benito, tomo primero, Madrid, por Gregorio Rodríguez, 1645; tomo segundo, Madrid, por Gregorio Rodríguez, 1647]

[13] [Al margen] Christoval Heidmanni en su Europa, siue manuductio ad Geographiam cap. 4. n. ${ }^{\circ} 110$, trae esta misma noticia de Irlanda.

[(Cristóbal Heidmann, $\uparrow$ 1627) Europa siue manuductio ad geographiam ueterem, Wolferbyti, sumptibus Conradi Bunouis, 1658.]

[14] [Nota 10] Comest. in Genes. cap. 24.

[(Pedro Comestor, $\dagger$ ca. 1179) Historia scholastica, Matriti, ex officina Antonii Gonzalez de Reyes, 1699]

[15] [Nota 11] Geral. y Ortelio apud Insti. Ethiop. Sal. Part. 2a . Lib. 3. ${ }^{o}$ cap. 4. ${ }^{\circ}$ no cito el autor porque le faltaba el principio, solo sé que es jesuita.

[(Abraham Ortelio, 1527-1598) Theatrum orbis terrarum, Antuerpiae, extat in officina Plantiniana, 1612]

[16] [Nota 12] Sur. die $1^{\text {a }}$. Julii in vit. S. Eparmach. al margen.

[(Lorenzo Surio, 1522-1578) Vitae sanctorum siue res gestae martyrum, confessorum atque sanctarum virginum, Bresciae, typis societatis Brixiensis, 1601].

CRISIS DEL $4 .^{\circ}$ DISCURSO INTITULADO PROFECÍAS SUPUESTAS

[17] [Nota 13] Senens. Bibliot. Lib. 2. ${ }^{\circ}$ vô. Sibyl. oracul.

[(Sixto de Siena, O.P., 1520-1569) Bibliotheca sancta, Venetiis, apud Franciscum Franciscum Senensem, 1574]

[18] [Nota 14] Pined. Monarq. Lib. 2. ${ }^{\circ}$ cap. 8. $.^{\circ} \S 2 .^{\circ}$

[(Juan de Pineda, ¿1513?-¿1593?) Los treinta libros de la Monarquía eclesiástica o Historia universal del mundo, divididos en cinco tomos, Barcelona, por Jerónimo Margarit, 1620]

[19] [Al margen] Cumea Sibyla $1^{\mathrm{a}}$. / Cumana $2^{\mathrm{a}}$. / Pérsica $3^{\mathrm{a}}$. / Helespóntica

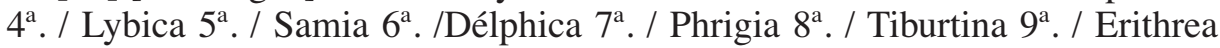
$10^{\mathrm{a}}$. Las mismas, y por este mismo orden numera Diego López en el Comento, y anotaciones de las Obras de Publio Virgilio Marón, $4^{\text {a }}$ Ecloga fol. 36, citando al Obp. de Coria Dn . García de Galarza Lib. 5 . Evangelic. Institutionum.

[(Diego López, s. XVII) Las obras de Publio Virgilio Marón, traducido en prosa castellana, Madrid, 1721]

[20] [Nota 15] Beda Lib. $1^{\circ}$. Côment. in Lucam. 
[Venerabilis Bedae operum tomus quintus in Nouum Testamentum, Coloniae, apud Ioannem Wilhelmum Friessem iuniorem, 1688]

[21] [Nota 16] S. Procop. Ita Simon Metaphrast. apud Sur. Mense Jullij (sic) die $8 .^{\circ}$ in vita S. Procop. $3 .{ }^{\circ}$

[22] [Nota 17] Sosom. Lib. 2. ${ }^{\circ}$ Ecclesiast. Histor. cap. 1. ${ }^{\circ}$ apud Sur. Mai. die

[23] [Nota 18] Señeri El Yncrédulo sin escusa cap. 17. $§ .13$.

[(Pablo Señeri, S. I., 1624-1694) El incrédulo sin excusa, parte primera y parte segunda, por Juan García Infanzón, Madrid, 1696]

[24] [Nota 19] A Lapide in Epist. ad Thesal. 2..$^{\circ}$. ${ }^{\circ}$ 57. Pisa en muchos lugares de sus Conformidades. Comest. Histor. Daniel. Vissio 4. ${ }^{a}$ Histor. Ecclesiast. Lib. 2. ${ }^{\circ}$ cap. 1. $^{\circ}$ apud Surium die $3^{\text {a }}$ Maij de invent. S. Crucis. S ${ }^{\text {ta }}$. Catarina Martir de Alexandría alegó al orador gentil el testimonio de una Sybila. Surius in eiusd. vit. 25 Novemb.

[a) (Cornelio a Lápide, S. I., 1567-1637) Commentaria in omnes Diui Pauli Epistolas, Coloniae \& Lugduni, apud Fratres de Tournes, 1732. b) (Bartolomé de Pisa, O.F.M.) Liber aureus inscriptus liber conformitatum uitae beati Francisci ..., Bononiae, apud Alexandrum Benatium, 1590. c) Cf. 14. d) Homiliae seu sermones in Euangelia, Lugduni, apud Sebastianum de Honoratis, 1557]

PROFECÍAS DE SAN MALAQUÍAS DEFENDIDAS

[25] [Nota 20] Sixt. Senens. Bibliot. Sanct. lib. 2. ${ }^{\circ}$ Vô. Salomon. fol. 106. ${ }^{\circ}$ [Cf. 17]

[26] [Nota 21] Lupo sup. Edict. S. Inquisit. Part. 3. ${ }^{\text {a }}$ Lib. XV. Artic. 4. ${ }^{\circ}$ Dific. $3 .^{\mathrm{a}}$

[(Ignacio Lupo de Bergamo) Noua lux in edictum S. Inquisitionis, Bergomi, typis Marci Antonii Rubei, 1648]

[27] [Nota 22] D. Bernard. in vita S. Malach. §. Percunctatus aliquando, \& ${ }^{\mathrm{a}}$.

[Diui Bernardi opera, Venetiis, ex typographia Salicata, 1616]

[28] [Nota 23] Rupert. apud Ribera in 12. Prophet. in Praelud. $1 .^{\circ}$ n. ${ }^{\circ}$ X. ${ }^{o}$

[(Francisco Ribera, S.I., 1537-1591) In librum duodecim prophetarum commentarii, Duaci, ex officina typographica Baltazaris Belleri, 1611]

[29] [Nota 24] Deuter. cap. 18. vvº 21 y 22.

RESPÓNDENSE LAS OBJECIONES

[30] [Nota 26] $1^{\mathrm{a}}$ ad Corinth. cap. 12. ${ }^{\circ}$ v. 10.

[31] [Nota 27] D. Bonava. in Hexam. Serm. 20. Los Paganos al leer las pro-

Hispania Sacra, LXI

124, julio-diciembre 2009, 621-647, ISSN: 0018-215-X 
fecías del Antiguo Testamento y viendo la grande claridad con que hablaban de Christo y de la Yglesia, no se persuadían a que no las havían inventado los cristianos engañadores; después de los sucessos acontecidos, dize S. Augustín (Serm. 62 vel 67 de div.): Vidistis ita fieri, et tamquam prędicta sint, scripsistis. Lo mismo arguie Feijoo de las profecías de San Malaquías; y tiene este argumento la misma fuerza que el de los paganos contra la Yglesia.

[a) Sancti Bonauenturae opera omnia, Lugduni, sumptib. Phil. Borde, Laur. Arnaud et Petri Borde, 1668. b) D. Aurelii Augustini Hipponensis episcopi operum tomus X, continens sermones..., Parisiis, s.n., 1586]

[32] [Al margen] (a) Assí llama Comines (En las mems. de Luis $11^{\circ}$ de Francia cap. 128. Lit. Q) a una red de hierro con recias varas: Rastillo.

[(Felipe Comines, 1445-1509) Las memorias de Felipe de Comines las quales contienen la historia de los reyes de Francia, Luis undécimo y Carlos octavo, tomo primero (y segundo), Amberes, por Henrico y Cornelio Verdussen, 1714]

[33] [Nota 28] Y Ossuna Memorias Sagradas.

[(Martín de Ossuna y Rus, O.C.D.,) Memorias y recuerdos de lo sagrado y real de la República de Dios, primera y segunda parte, en Sevilla, por Juan Cabezas, 1679]

[34] [Nota 29] Santa Mar. España Triunfante. cap. 52.

[(Fr. Antonio de Santa María, O.C.D., † 1704) España triunfante y la Iglesia laureada en todo el globo del mundo por el patrocinio de Maria Santísima en España, en Madrid, por Julián de Paredes, 1682]

[35] [Nota 31] Sapient. cap. 4..$^{\circ}$ v. ${ }^{\circ} 8 .^{\circ}\left[-9 .^{\circ}\right]$.

[36] [Nota 32] Scot. Lib. 2. ${ }^{\circ}$ ssârum Disct. 17. ${ }^{\text {a }}$

[Dunsii Scoti opera omnia, Lugduni Batauorum, 1639]

[37] [Nota 33] Ecclesiast. cap. 48. v. ${ }^{\circ} .^{\circ}$

[38] [Nota 34] Isai. cap. 37. v. $22 .{ }^{\circ}$

[39] [Nota 35] Jerem. cap. 2..$^{\circ}$ v. ${ }^{\circ} 13 .^{\circ}[=$ Lam 2, 13]

[40] [Nota 36] Idem. cap. $14 .^{\circ}$ v. 17.

[41] [Nota 37] Pinto in Esai. cap. $1^{\circ}$ et 37.

[(Fr. Héctor Pinto, Jer., 1528-1584) Operum omnium latinorum tomus primus, qui in Esaiam, Threnos, Ezechielem, Danielem et Nahum commentarios comprehendit, Lutetiae Parisiorum, apud Nicolaum Buon, 1617]

[42] [Nota 38] Nieremb. Occult. Philosoph. Lib. 1. ${ }^{\circ}$ cap. 53. De la mudanza de la natural. [Cf. 6].

[43] [Nota 39] Aug. Tom. 11. vel 9. ${ }^{\circ}$ según las impress. Tract. 23 de Antixpto.

[44] [Nota 40] Joann. 3. ${ }^{\circ}$ v. $^{\circ} 14 .^{\circ}[=34]$

[45] [Nota 41] Riber. in Hoseam cap. 1. ${ }^{\circ}$ n. ${ }^{\circ}$ IV. [Cf. 28]. 
[46] [Nota 42] Greg. López Paraph. de el Apocal. cap. 20.

[(Gregorio López, 1542-1596) Paráfrasis y declaración del libro canónico del Apocalipsis, $1626, \mathrm{Ms}$.]

[47] [Nota 43] Job. cap. 6. ${ }^{\circ}\left[\mathrm{v}^{\mathrm{o}} 8\right]$.

[48] [Al margen] El Venerable Señeri en el Yncrédulo sin escusa, cap. ${ }^{\circ} 18 .^{\circ}$ n. ${ }^{\circ}$ 9. ${ }^{\circ}$ dize: La urdimbre de aquella tela que ahora se escoge en nuestra presencia delineó, mucho tiempo ha [...]. [Cf. 23].

[49] [Nota 44] Riber. in Apocal. cap. 20. $n^{\circ}$ 73. A Lapide in Epist. 2a ad Thesal. cap. $2{ }^{\circ}$ v. 79.

[a) In sacram B. Ioannis Apostoli \& Euangelistae Apocalypsin commentarii, Duaci, apud Gerardum Patte, 1623. b) Cf. 24 a]

[50] [Nota 45] Iob. cap. 6. ${ }^{\circ}$ [v. $\left.{ }^{\circ} 12\right]$.

[51] [Nota 46] Hierarq. Carmelit. cap. 15. fol. mihi 595.

[(Juan Pinto de Victoria, O.C.) Jerarquía carmelitana y gloria de los santos del Monte Carmelo, Valencia, por Juan Crisóstomo Garriz, 1626]

RESPÓNDESE AL OPOSSITOR PALMENSE

[52] [Nota 47] Pisa Conformit. Lib. 1. ${ }^{\circ}$ fruct. 1. ${ }^{\circ}$ pro 2. ${ }^{\text {a }}$ Part. [Cf. 24 b]

AdDICIÓN AL ASSUMPTO DE EL $\S .94 .^{\circ}$

[53] [Nota 48] Mañer. Antith. D. ${ }^{\circ} 1 .^{\circ}$ n. ${ }^{\circ} 6{ }^{\circ}$

[(Salvador José Mañer, 1676-1751) Anti-Theatro crítico sobre el primero y segundo tomo del Teatro Crítico Universal del $R^{m o}$. Benito Feijoo, Madrid, en casa de Juan de Moya, 1729]

[54] [Nota 49] Señeri. El Yncrédulo sin escusa. Part. 2. cap. 23. n. ${ }^{\circ} 15$. $^{\circ}$ [Cf. 23].

ADDICIÓN EN QUE SE DEFIENDEN LAS CARTAS PROFÉTICAS DEL GRAN PADRE SAN FRANCISCO DE PAULA, Y SE RESPONDE A LAS OBSERVACIONES DEL M. R. PADRE FR. BENITO FEIJOO, MAESTRO GENERAL DE LA ORDEN DE EL GLORIOSO PADRE S. BENITO.

[55] [Nota 50] Alvar. tom. $6 .^{\circ}$ en el fin de la vida de Alex. ${ }^{\circ}$ VI. ${ }^{\circ}$

[(Cristóbal Álvarez, O.F.M.,) Historia de la vida y hazañas de Ioab y un resumen de los póntifices y cardenales que han tenido las religiones de Santo Domingo, San Francisco y San Agustín, León, s.n., 1684]

Hispania Sacra, LXI

124, julio-diciembre 2009, 621-647, ISSN: 0018-215-X 
[56] [Al margen] (*) Todo el Capítulo General de la Religión Dominicana en sus Constituciones, impressas en Roma, año de 1690, afirma la innocencia del Padre Savonarola diziendo que murió quemado, en pública plaza, por la rabia y embidia de algunos hombres facinerosos. El Maestro Dominicano Jacobo Quetif in nota ad cap. 21. pag. 112, apud Vindicias históricas de Segura, escrivió sin miedo, año de 1674: Hieronymum vere catolicum, Ecclesiae filium nulliusque fermentatae doctrinae professione foedatum, sed et vitae puritate et doctrina illibata praeditum, Ecclesiaeque Catolicae (cuius aestuabat zelo) semper obedientissimum, nullus hactenus, nisi lividus, ierit inficias. Segura, que escribió año de 1735 , dize que ningún magistrado ha notado tal elogio.

[(Jacinto Segura, O.P., 1668-1751) Vindicias históricas por la inocencia de Fr. Gerónimo Savonarola de la Orden de Predicadores, Valencia, por Antonio Balle, 1735]

[57] [Al margen] El V.e Señerí en el Yncrédulo sin escusa, cap. ${ }^{\circ} 18 .^{\circ} \mathrm{n} .^{\circ} 4 .^{\circ}$ dize: Juan Francisco Pico de Mirándula, príncipe en quien fue difícil juzgar quál prenda sobresalía más, si la nobleza de la sangre o la prudencia, la pie$\mathrm{dad}, \&^{a}$. Este elogio y juizio le mereció a un hombre, tan hombre, como el Padre Señerí, el defensor del Padre Savonarola, que por sólo la amistad se desbarró sin límite en sus elogios. ¿No es estupenda temeridad? Sixto Senens. Bibl. Sanct. Lib. 3. ${ }^{\circ}$ De Prophetica exposit: Hieronymus Savonarola vir ardentissimi spiritus \& ${ }^{\mathrm{a}}$., et Lib. 4. ${ }^{\circ}$ ibi. lit. H: Hieronymus Savonarola Ferrariensis, Ord. Praedicat., excellentis ingenij vir multarumque scientiarum copia praeditus ... sanctitatis opinione omnibus admirandus \& ${ }^{\mathrm{a}}$. El Doctor Yllescas, en su Pontifical Tom. 2. ${ }^{\circ}$ Lib. $6{ }^{\circ}$ Histor. de Alex. $6 .{ }^{\circ} \S$. V. ${ }^{\circ}$, no escriviendo a favor del Padre Savonarola, dize que oyó dezir al doctíssimo Padre Maestro Fray Mancio de la Orden de Santo Domingo que, de testigo fidedigno y familiar del Obispo Remolino, oyó afirmar que por toda la vida le duró al Obispo el arrepentimiento de haver pronunciado esta sentencia y que, para satisfación della delante de Dios, ayunava tres días en la semana.

[a) Cf. 23. b) Cf. 25. c) (Gonzalo de Illescas, 1565-1633) Historia pontifical y católica, en la cual se contienen las vidas y hechos notables de todos los Sumos Pontífices Romanos, Madrid, en la Imprenta Real, 1613]

[58] [Nota 53] In Hexameron. D. Bonau ${ }^{\mathrm{a}}$. [Cf. 31]

[59] [Nota 54] Amos cap. 3. ${ }^{\circ}$ v. ${ }^{\circ} 7 .^{\circ}$

[60] [Nota 55] Apud Maldon. in Math. cap. 20.

[(Juan Maldonado, S.I., 1533-1583) Commentarii in quattuor Euangelistas, Lutetiae Parisiorum, apud Ludouicum Billaine, 1668]

[61] [Nota 56] D. Thom. 1 ${ }^{\text {a }}$. Part. Q. 10.

[62] [Nota 57] Daniel cap. 7. ${ }^{\circ}$ v. 27.

[63] [Nota 58] Joach. Abb. In Concord. Evang. cap. 18. Apud Pisa in Conformit. Lib. $1^{\circ}$ fruct. $1 .^{\circ}$ et Alva Portent. grat. Tabul. $24^{\mathrm{a}}$. Apparat in fine. 
(a) Diuini uatis Abbatis Joachim liber concordiae Noui ac Veteris Testamenti, Venetiis, per Simonem de Luere, 1519. b) Cf. 24 b. c) (Pedro de Alva y Astorga, O.F.M. $†$ 1667) Naturae prodigium gratiae portentum, hoc est seraphici P. N. F. Francisci uitae acta, Matriti, in typographia Iullani de Paredes, 1651]

[64] [Nota 59] Esdras Lib. 4. ${ }^{\circ}$ cap. 12. ${ }^{\circ}$ v. 34.

[65] [Nota 59 bis] Aug. Quest. 31 in Genes.

[D. Aurelii Augustini, Hipponensis episcopi, quaestiones in Vetus Nouumque Testamentum, Lugduni, apud Sebastianum Honoratum, 1561]

[66] [Nota 60] Riber. In Abdiam. cap. 1. ${ }^{\circ}$. ${ }^{\circ}$ 37; et in Mich. cap. 5. $.^{\circ} .^{\circ} 40$, 41 et 45 .

[R. P. Francisci Riberae, Societatis Iesu, in duodecim prophetas minores commentarii, Coloniae Agrippinae, in officina Birckmannica, 1600]

[67] [Nota 61] Pereyr. in Genes. tom. 3. ${ }^{\circ}$ pag. 130 y siguientes. Etiam Valentia Christopolit ${ }_{3} \mathrm{Epu}_{3}$ contra Judęos Q. 1 ${ }^{\mathrm{a}}$. Arto. 3.

[a) (Benito Pereira, S.I., 1535-1610) Commentariorum et disputationum in Genesim tomus primus-quartus, Coloniae Agrippina, apud Antonium Hierat, 1621. b) (Jaime Pérez de Valencia, O.S.A., 1408-1490) Explanationes in centum quinquaginta Psalmos Dauidicos tractatuscontra Iudaeos, Venetiis, Bartholomaeus Rubinus, 1568]

[68] [Nota 63] Assí el Abb. Joach. In Hier. cap. 1. ${ }^{\circ}$

[Abbatis Ioachim diuina prorsus in Ieremiam prophetam interpretatio, Coloniae, apud Lodouicum Alectorium et haeredes Iacobi Soteris, 1577]

[69] [Nota 64] Esai. cap. 51. v. ${ }^{\circ}$ 14; et Idem cap.

[70] [Nota 65] Apud Alva Portent. grat. Tabul. Apparat. 3. ${ }^{a}$ [Cf. 63 c]

[71] [Nota 66] Rib. in Habac. cap. 2. ${ }^{\circ} .^{\circ} 5 .^{\circ}$ [Cf. 66]

[72] [Nota 67] Joach. ubi sup. in Concord. [Cf. 63 a]

[73] [Nota 68] Petr. Epistol. 2a ${ }^{\mathrm{a}}$ cap. 3. ${ }^{\circ}$ v. $9 .{ }^{\circ}$

\section{CRISIS DE LOS DISCURSOS PAYZANOS}

[74] [Nota 72] Murga Const. Synod. fol. 357.

[(Cristóbal de la Cámara y Murga, $†$ 1641) Constituciones Sinodales del Obispado de la Gran Canaria (1629), Madrid, 1634]

[75] [Nota 73] Peña Descrip. de las Islas de Can ${ }^{\text {. Lib. }} .^{\circ}$. $^{\circ}$ cap. $2 .{ }^{\circ}$

[(Juan Núñez de la Peña, 1641-1721) Conquista y antigüedades de las islas de Gran Canaria y su descripción, Madrid, en la Imprenta Real, 1676]

[76] [Nota 74] Dr. Christo Excelenc. y Antigued. de las Cans.

[(Cristóbal Pérez del Cristo, 1639-1705) Excelencias y antigüedades de las siete Islas de Canaria, Jerez de la Frontera, por Juan Antonio Tarazona, 1679]

Hispania Sacra, LXI

124, julio-diciembre 2009, 621-647, ISSN: 0018-215-X 
[77] [Nota 75] Botero Relac. Univers. 1. ${ }^{\text {a }}$ Part. Lib. 6. ${ }^{\circ}$ fol. 178.

[(Juan Botero, 1543-1617) Relaciones universales del mundo traducidas por Diego de Aguiar, Valladolid, por los herederos de Diego Fernández de Córdova, 1603]

[78] [Nota 76] Cortés Phison. y varios secretos, Trat. 4. ${ }^{\circ}$ fol. 36.

[(Jerónimo Cortés, $\dagger$ 1615) Fisonomía y varios secretos de naturaleza, en Valencia, Vicente Cabrera, impresor y librero, 1689]

[79] [Nota 77] Nieremb. Ocult. Philos. Lib. 2. ${ }^{\circ}$ cap. 60. [Cf. 6]

[80] [Nota 79] Cano De locis Theol. Lib. 11. cap. 4. ${ }^{\circ}$ [Cf. 1]

[81] [Nota 80] Nieremb. Philos. ocult. Lib. 1. ${ }^{\circ}$ de la Sympat. cap. 81. [Cf. 6]

[82] Nieremberg. Ocult. Philos. Lib. 2. ${ }^{\circ}$ del artif. de la natural cap. 58. [Cf. 6]

ISLA DE SAN BRENDÓN ENCUBIERTA

[83] [Al margen] 11. ${ }^{\circ}$ Opinión de Peña. Lo que dista de La Palma. [Cf. 75]

[84] a) El Doctor Christo en su libro Excelens' y Antigueds. de las Islas trae una noticia que conviene con ésta. Púsela en el original que fue a España, ahora caresco de él. [Cf. 76]

De[S]VANÉCENSE LAS OBSERVACIONES DE BENITO

[85] [Nota 89] Aug. de Civit. Dei cap. 9..$^{\circ}$

[Sancti Augustini Aurelii Hipponensis episcopi operum tomus septimus, continens libros XXII de civitate Dei, Antwerpiae, sumptibus Societatis, 1700]

[86] [Al margen] Algunos autores, que Mosés Barcephas refiere en el libro que escribió del Parayso, dizen que, como Adán fuesse colocado por Dios en el Parayso terrestre, que está apartado de el Orbe nuestro mediando immenso occéano, después arrojado de él por el pecado, por sus pies passó el occéano y vino a dar a nuestro Orbe. Apud Bnēdict. Pereyr. in Genes. lib. 4. ${ }^{\circ}$ Q. 3. ${ }^{a}$ fol. 415. Lit. B. [Cf. 67 a]

REPÍTESE MI JUIZIO PARTICULAR SOBRE EL JUIZIO UNIVERSAL DE BENITO

[87] [Nota 98] Hoseas cap. 8. v. ${ }^{\circ} .^{\circ}$

\section{ADICIÓN}

[88] [Nota 112] Comines capo. 194. [Cf. 32] 